\title{
Pneumomediastinum in a smoking free-base cocaine abuser during sexual intercourse
}

\section{Gianfranco Gioia* \\ Department of Clinical Medicine, Sapienza University of Rome, Italy}

Case: 21 -year-old man.

Chief complaint: Retrosternal chest pain.

Clinical history: There were no pathologies in family history. He did not take any medications. He was smoking 10 cigarettes daily. He was a habitual cocaine user. The patient had a blood pressure of $120 / 80$ $\mathrm{mmHg}$, a resting heart rate of 73 beats/minute, a respiratory rate of 16 breaths/minute, an oxygen saturation of $98 \%$, and no temperature. The main symptom was an initial sharp retrosternal chest pain starting 5 hours before in the course of free-base cocaine smoking. Dyspnea and retrosternal pain were increasing with breath and chest movements. The pain was intensifying 2 hours earlier during sexual intercourse with a female partner. Then, the retrosternal pain was constant as regards intensity and localization. Subcutaneous emphysema of the neck was palpable on physical examination. Inspiratory effort and elicited rib pain was evident on chest examination. Cardiopulmonary auscultation and electrocardiography were normal.

Laboratory findings: Blood tests were normal; urine drug analysis was positive for cocaine.

\section{Image findings}

Chest X-ray (CXR) revealed clear lung fields, pneumomediastinum (PM) and emphysema in the soft tissues between the muscles of the neck (Figure 1a). Pulmonary computed tomography (CT) without contrast showed pneumomediastinum (PM), i.e. air dissecting tissue planes extending in the soft tissues of the neck, including the muscles, the nerves, the right rear second back rib and the ipsilateral front first and second anterior rib, all the mediastinal recesses (also anterior) and the bilateral peribronchial and paraesophageal spaces until the diaphragmatic hiatus. CT also showed a solution of continuity of the right postero-lateral portion of the trachea with adjacent minimum hypo-dense material (Figures 2a, 3a, 4a). In emergency department, the application of human fibrin glue by means of bronchoscopy was used to seal the tracheal lesion. CXR showed complete resolution of the PM and subcutaneous emphysema after 12 days (Figure 1b). Chest CT without contrast also revealed complete resolution at 15 days (Figures $2 b, 3 b, 4 b)$.

\section{Discussion}

$\mathrm{PM}$ was consequent to tracheal rupture due to Valsalva maneuver during both smoking free-base cocaine use and sexual activity. PM consequent to barotrauma is a possible finding in patients with cocaineinduced pulmonary disease [1]. Barotrauma is a complication related to cocaine inhalation [2] or crack smoking [3]. It is the consequence of an increased airway and intrathoracic pressure due to intentional production of Valsalva maneuvers and episodes of coughing after smoking, in an attempt to absorb the maximal amount of drug. The rupture of alveoli into the interstitium and the mediastinum frequently produces PM after over-distension against a closed glottis. Our case report is particular as regards the etiology of PM, i.e. tracheobronchial tree laceration consequent to Valsalva maneuvers and tracheobronchial wall fragility due to the direct toxicity of the cocaine on the lung tissue after repeated inhalational exposure to illicit drug particles of 2.5-6 $\mu \mathrm{m}$ [4]. Cigarette use and illicit cocaine abuse are important elements of clinical history because the incidence of PM is high in smokers and drug abusers. Both inhaled and intravenous forms of cocaine abuse can result in well-recognized respiratory acute and chronic complications such as nasal septum perforation, pulmonary
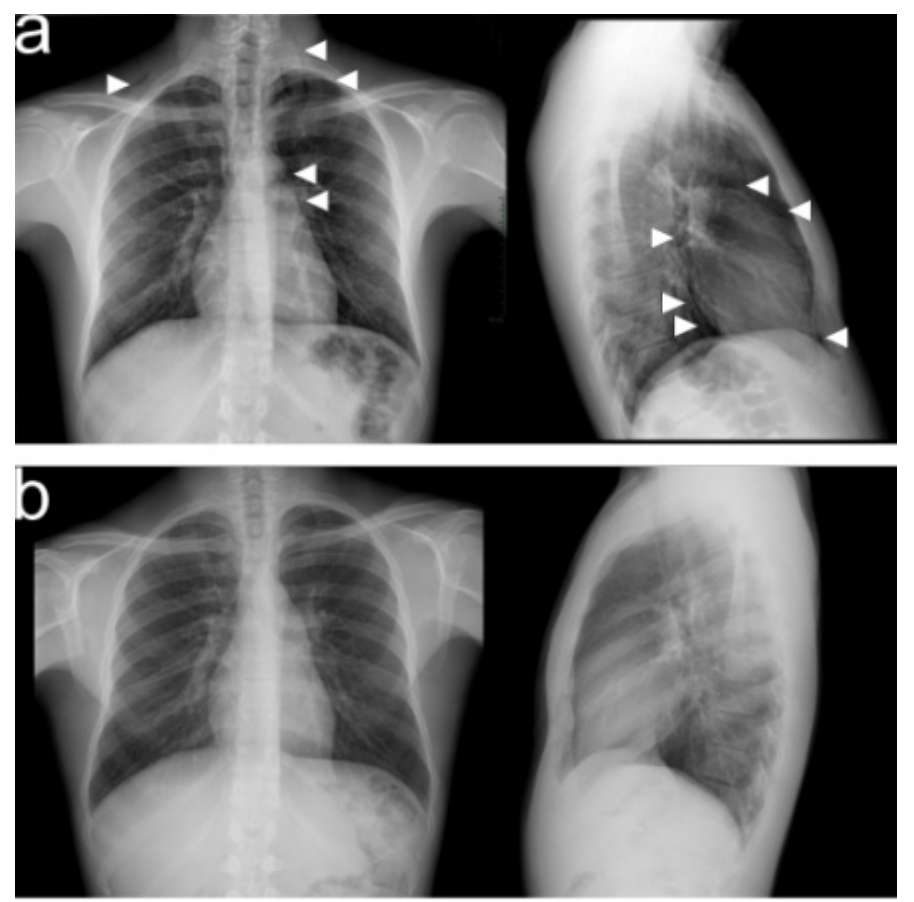

Figure 1. 21-year old man with PM. Paracardiac radiolucent band (white arrow-heads) and air levels in the subcutaneous tissues of the neck (white arrow-heads) on postero-anterior CXR; air levels in the mediastinum (white arrow-heads) on lateral CXR (a); complete resolution of PM and subcutaneous emphysema on CXR after 12 days (b).

Correspondence to: Gianfranco Gioia, Department of Clinical Medicine, Sapienza University of Rome, Italy, Viale del Policlinico, Rome, Italy; Tel/ Fax: +39064380480; E-mail: gioiag86@hotmail.it

Received: August 25, 2017; Accepted: September 23, 2017; Published: September 25, 2017 

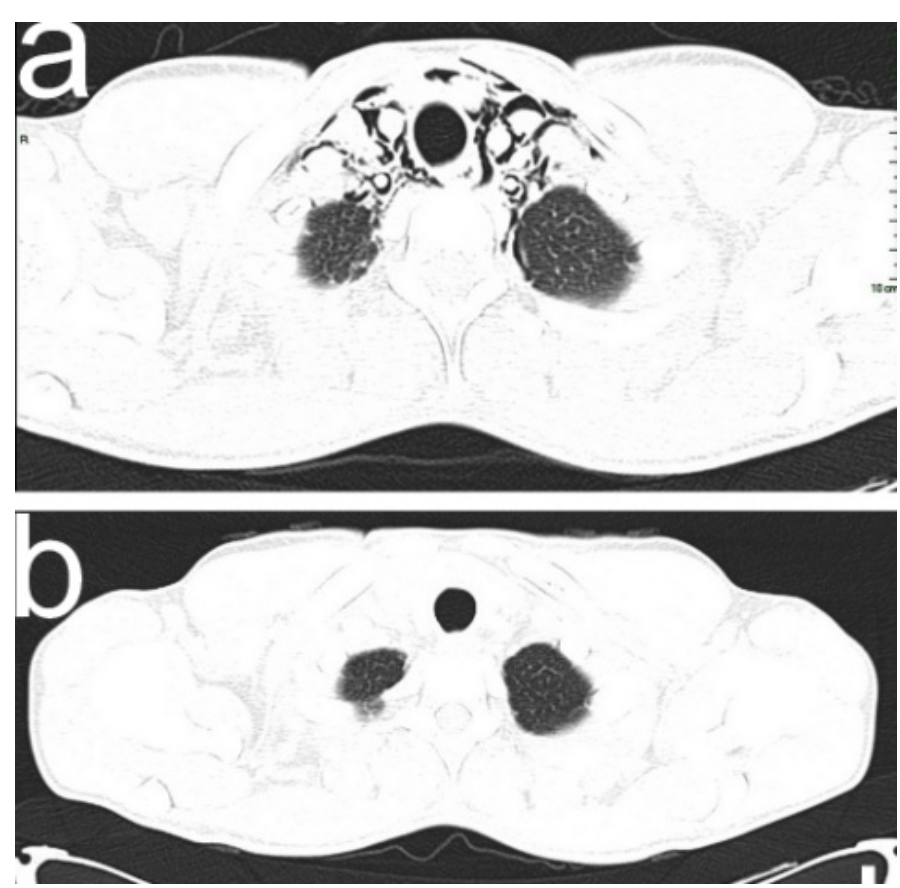

Figure 2. Air dissecting into the mediastinal spaces and the cervical soft tissues (a) and complete resolution (b) on CT scan in axial plane after 15 days. CT scan was performed with Siemen's somatom sensation 16 slices, 130-217 mAs, $120 \mathrm{kV}$ energy, and slice thickness was $1.5 \times 1.5 \mathrm{~mm}$. No contrast was used (a). The second CT scan was also performed with Siemen's somatom sensation 16 slices, 200-217 mAs, $120 \mathrm{kV}$ energy, and slice thickness was 1.5 x $1.5 \mathrm{~mm}$. No contrast was used (b).

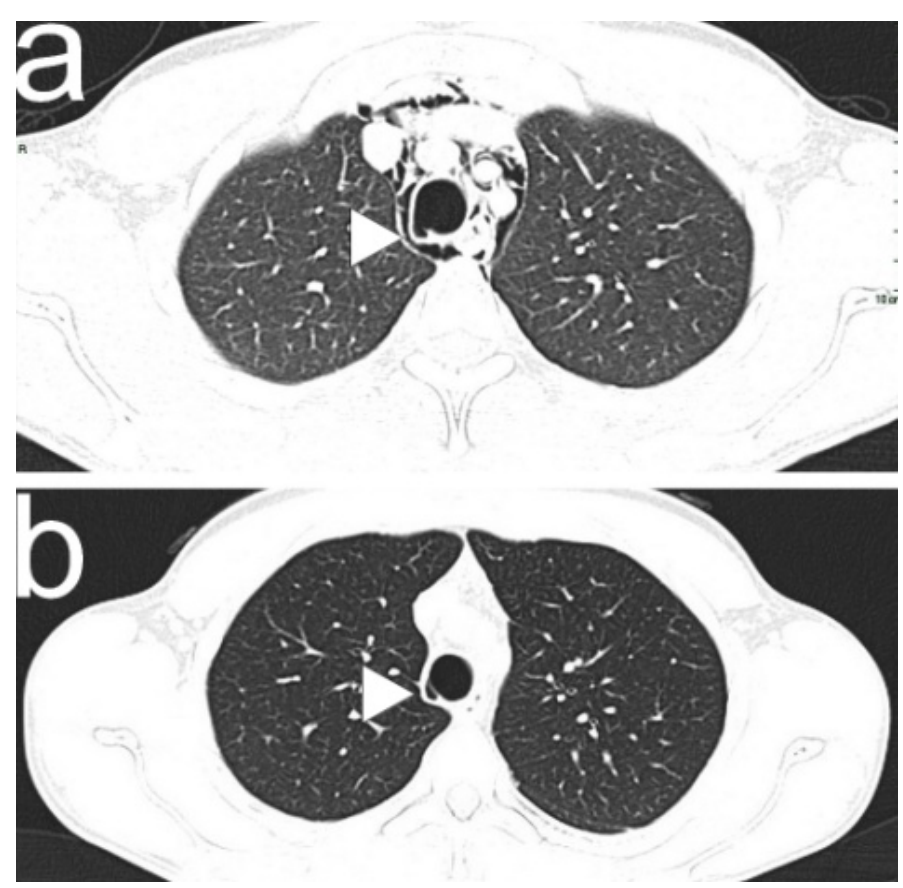

Figure 3. PM and the solution of continuity (white arrow-head) of the right postero-latera portion of the trachea (a); complete resolution of PM, closure of the tracheal solution of continuity with residual small pocket area $(10 \times 5 \times 5 \mathrm{~mm})$ (white arrow-head) on the right lateral side of the tracheal wall adjacent to the previous tracheal laceration treated endoscopically, and a good barrage of scar tissue at that level on CT scan in axial plane (b).

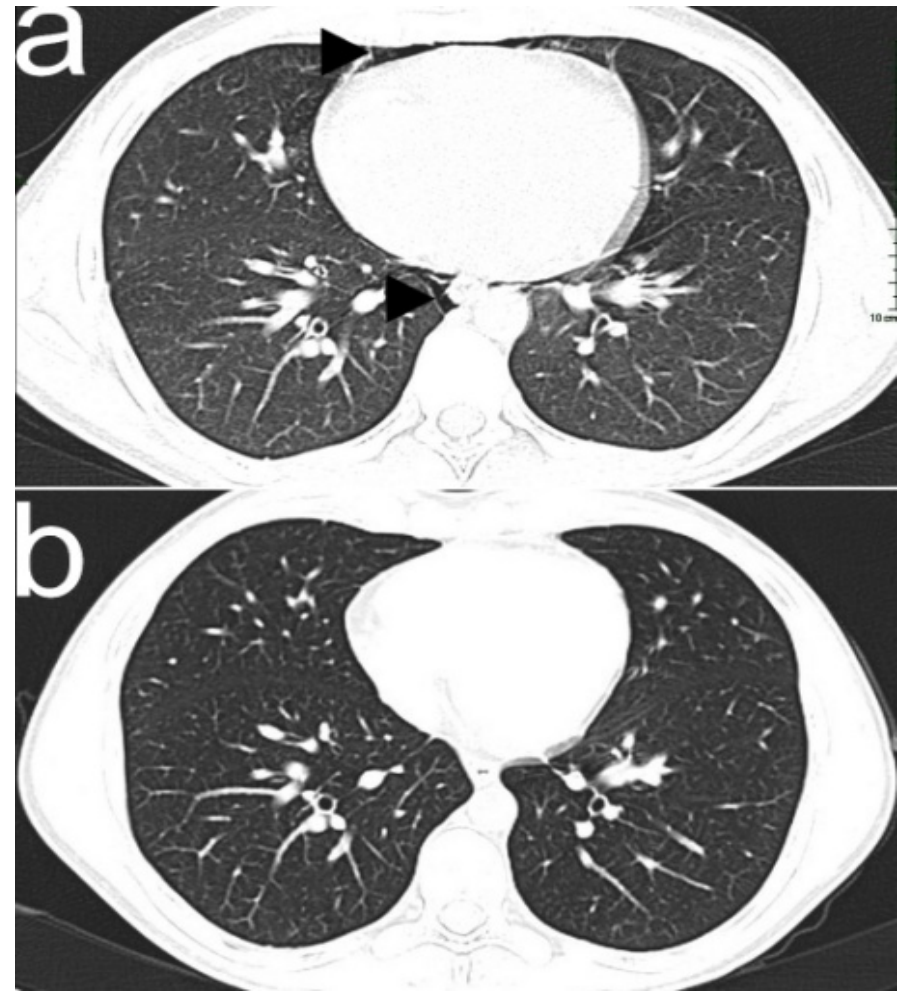

Figure 4. Air in anterior and posterior paracardiac regions (black arrow-heads) (a) and complete resolution on chest CT scan in axial plane (b).

hypertension, pneumothorax, PM, airway burns, and lung syndromes (interstitial lung disease, alveolar hemorrhage, reactive airway disease, pulmonary edema, pulmonary granulomatosis, infections, foreign body aspiration, infections, bronchoconstriction, and thermal injuries) [5]. PM occurs when cocaine is smoked, but can also occur when cocaine is nasally inhaled $[6,7,8]$. PM is part of the differential diagnosis for chest pain, particularly in young people, smokers, and drug abusers. The differential diagnosis of cocaine-induced chest pain includes PM, pneumothorax, pneumopericardium, aortic dissection, pulmonary hemorrhage, acute coronary syndrome, and coronary artery vasospasm [9]. The clinical history, the physical examination, the hemodynamic stability and the lack of blood analysis alterations are essential to exclude other alternative causes. Postero-anterior and lateral CXR and CT have definitely ruled out alternative causes of PM such as thoracic trauma, oesophageal rupture, and pulmonary infection. CXR and CT are important tools to investigate PM due to tracheobronchial tree laceration [10]. The analysis of cases of 104 patients affected by spontaneous PM showed that the main predisposing factors are young age, male sex, age less than 30 years, asthma, chronic bronchitis, and drug use [11]. In our case, illicit drug use is the predisposing factor and sexual physical exercise is the precipitating factor. In the MEDLINE, we found patients with tracheobronchial rupture and PM secondary to smoking free-base cocaine [12], but no cases concerning the relationship between tracheobronchial laceration and sexual activity. We found only one case report describing concomitant air in the epidural space, mediastinum and pericardium after illicit drug use and engagement in sexual activity [13], and one case report with 
concomitant PM and sexual intercourse [14]. The presenting symptoms and signs evidenced in our patient, such as retrosternal chest pain increasing with breath and thorax movements, bilateral tenderness on acupressure of sternum-chondral joints, subcutaneous emphysema involving the neck and shortness of breath with normal vital signs, are typical of PM [15]. Symptoms subsided after 24 hours and signs after 72 hours from the therapeutic bronchoscopy. The patient was observed for 15 days with continuing outpatient follow-up. Medical management included intravenous analgesia, rest, and initial oxygen therapy. The main treatment was the use of human fibrin glue during bronchoscopy aimed at closing the tracheobronchial rupture. In conclusion, invasive procedures should be based on a high degree of clinical suspicion for bronchial tree laceration.

\section{References}

1. Mégarbane B, Chevillard L (2013) The large spectrum of pulmonary complications following illicit drug use: features and mechanisms. Chem Biol Interact 206: 444-451. [Crossref]

2. Cabañas JG, Brice JH, Woodward K (2009) An unrecognized presentation of cocaineassociated pneumomediastinum in the prehospital setting. Prehosp Emerg Care 13: 384-387. [Crossref]

3. Blasco V, Nafati C, Reydellet L, Harti-Souab K, Albanèse J (2014) Spontaneous pneumomediastinum secondary to inhalation of crack. Ann Fr Anesth Reanim 33: 282 283.

4. Devlin RJ, Henry JA (2008) Clinical review: Major consequences of illicit drug consumption. Crit Care 12: 202. [Crossref]
5. Tseng W, Sutter ME, Albertson TE (2014) Stimulants and the lung: review of literature. Clin Rev Allergy Immunol 46: 82-100. [Crossref]

6. Bond R, Duncan E, Nightingale A (2015) Image of the month: Chest pain after cocaine use. Clin Med (Lond) 15: 497-498. [Crossref]

7. O'Connor J, Renton B (2017) Two cases of cocaine nasal insufflation-induced pneumomediastinum. Br J Hosp Med 78: 233. [Crossref]

8. Soares DS, Ferdman A, Alli R (2015) Subcutaneous emphysema and pneumomediastinum following cocaine inhalation: a case report. J Med Case Rep 9: 195. [Crossref]

9. Chudasama K, Seenath M, Gourevitch D (2010) Pneumomediastinum after cocaine use: an unusual aetiology. J Surg Case Rep 2010: 3. [Crossref]

10. Almeida RR, Zanetti G, Souza AS, Souza LS, Silva JL, et al. (2015) Cocaine-induced pulmonary changes: HRCT findings. J Bras Pneumol 41: 323-330. [Crossref]

11. Abakumov MM, Shamba KhL, Danielian ShN (2010) Spontaneous emphysema of the mediastinum. Khirurgiia (Mosk) 10: 17-21.

12. Schweitzer VG (1986) Osteolytic sinusitis and pneumomediastinum: deceptive otolaryngologic complications of cocaine abuse. Laryngoscope 96: 206-210. [Crossref]

13. Allen CJ, Teisch LF, Stahl KD (2015) Spontaneous pneumomediastinum, pneumopericardium and epidural pneumatosis: insights on clinical management. Acute Card Care 17: 20-23.

14. Packham CJ, Stevenson GC, Hadley S (1984) Pneumomediastinum during sexual intercourse. Br Med J (Clin Res Ed) 288: 1196-1197. [Crossref]

15. Macia I, Moya J, Ramos R, Morera R, Escobar I, et al. (2007) Spontaneous pneumomediastinum: 41 cases. Eur J Cardiothorac Surg 31: 1110-1114. [Crossref]

Copyright: (C2017 Gioia G. This is an open-access article distributed under the terms of the Creative Commons Attribution License, which permits unrestricted use, distribution, and reproduction in any medium, provided the original author and source are credited. 